\title{
Influence of competing notches on the fatigue strength of cut plate edges
}

\author{
P. Diekhoff ${ }^{1}$ (I) $\cdot$ J. Drebing $^{1} \cdot$ J. Hensel $^{1} \cdot$ Th. Nitschke-Pagel $^{1} \cdot$ K. Dilger $^{1}$
}

Received: 5 March 2020 / Accepted: 11 February 2021 / Published online: 6 March 2021

(C) The Author(s) 2021

\begin{abstract}
Material fatigue is one of the elementary causes of damage in steel construction besides corrosion and abrasion. Design recommendations require that weld seams are placed in less stressed areas due to the crack-sensitive nature of the welded areas. As a result, unwelded areas of the components such as free cut plate edges gain technical and economic relevance as locations for potential fatigue cracks. In the metal processing industry, different thermal cutting processes are frequently used. During the process, unwanted boundary conditions can lead to undesired cuts in the component geometry during the cutting process. These process dysfunctions lead to incorrect components and to rejects. This article presents results of fatigue test data of oxy-fuel thermal cut edges of defect-free and faulty repair-welded samples to investigate the influence of competing notches on the cut edge. Specimens are made from construction steels S355N and S690Q of a 20-mm-thick plate. The presented data shows that the fatigue strength of the damaged cut edges can be recovered by the repair procedure and does not show any reduction of the fatigue strength due to the determined pores or other metallurgical notches of the repaired section.
\end{abstract}

Keywords Fatigue strength $\cdot$ Thermal cutting $\cdot$ Cut edge $\cdot$ High strength steel $\cdot$ Surface quality $\cdot$ Hardness $\cdot$ Competing notches $\cdot$ Cutting speed

\section{Introduction}

Components and steel constructions, which are exposed to cyclic loads, are subject to the phenomenon of material fatigue which occurs in numerous fields of applications such as crane, aircraft, and platform construction [1]. Material fatigue is one of the elementary causes of damage in steel construction in addition to corrosion and wear and includes more than $33 \%$ of all known component damages [2]. This is caused by cracking and its growth and often ends in complete failure. Cracks tend to start at locations of increased stress concentration resulting from notches, cross-sectional changes, or material defects [3].

Recommended for publication by Commission XIII - Fatigue of Welded Components and Structures

P. Diekhoff

p.diekhoff@tu-braunschweig.de

1 Institute of Joining and Welding, Technische Universität Braunschweig, Langer Kamp 8, D-38106 Braunschweig, Germany
The resistance of a component to the entire fatigue process is often referred to as fatigue strength.

Since many designs require special component shapes, they are usually separated in the industry by thermal cutting processes such as laser beam cutting, oxy-fuel cutting, water jet cutting, or plasma cutting. Depending on the process parameters of the different cutting methods, the cut edges have a high or inferior quality, which influences the fatigue strength [4-7].

Design recommendations require that weld seams are placed in lowly stressed areas due to the crack-sensitive nature of the welded areas, and conventional post-treatment methods, like shot peening or high frequency mechanical impact (HFMI), are used [8]. As a result, unwelded areas of the components such as free cut plate edges gain technical and economic relevance as locations for potential fatigue cracks [4]. Due to increasing use of higher strength steels due to advantages such as lower production costs, reduction of $\mathrm{CO}_{2}$ emissions, and weight reduction, consideration of unwelded areas becomes even more important. By using higher-strength steels, the sheet thicknesses can be reduced, and consequently, the nominal stress level increases [9]. In particular, thermal cut 
Table 1 Material properties

\begin{tabular}{llll}
\hline Material & Yield strength $R_{\mathrm{eH}}(\mathrm{MPa})$ & $\begin{array}{l}\text { Maximum tensile } \\
\text { strength } R_{m}(\mathrm{MPa})\end{array}$ & Elongation at fracture (\%) \\
\hline S355N (3 specimens tested) & $372-424$ & $560-570$ & $27-32$ \\
S690Q (3 specimens tested) & $769-866$ & $790-904$ & $9-15$ \\
\hline
\end{tabular}

Table 2 Chemical composition (\%)

\begin{tabular}{lllllllll}
\hline Material & $\mathrm{C}(\%)$ & $\mathrm{Si}(\%)$ & $\mathrm{Mn}(\%)$ & $\mathrm{P}(\%)$ & $\mathrm{Cr}(\%)$ & $\mathrm{Mo}(\%)$ & $\mathrm{Ni}(\%)$ & $\mathrm{CEV}(\%)$ \\
\hline $\mathrm{S} 355 \mathrm{~N}, 1$ & 0.11 & 0.38 & 1.41 & 0.011 & 0.030 & 0.016 & 0.036 & 0.36 \\
$\mathrm{~S} 355 \mathrm{~N}, 2$ & 0.16 & 0.37 & 1.43 & 0.010 & 0.033 & 0.013 & 0.035 & 0.41 \\
$\mathrm{~S} 690 \mathrm{Q}, 1$ & 0.08 & 0.25 & 1.19 & 0.010 & 0.32 & 0.30 & 0.075 & 0.41 \\
$\mathrm{~S} 690 \mathrm{Q}, 2$ & 0.11 & 0.25 & 1.19 & 0,010 & 0.31 & 0.31 & 0.078 & 0.44 \\
\hline
\end{tabular}

edges must be considered and evaluated due to the geometrical and metallographical conditions. In addition to the heataffected zone, unwanted boundary conditions can lead to undesired cuts in the component geometry during the cutting process. These process dysfunctions lead to incorrect components and to rejects. Besides the requirements for the quality characteristics of the components in EN 1090 [10] and further in ISO 9013 [11], legislation on product liability in some industries does not allow repair welds to be considered admissible, resulting in economically undesirable rejects.

The influence of thermal cutting edges and their different qualities on fatigue strength has already been examined in previous investigations, for example, by Sperle [4], Remes et al. [12], Stenberg et al. [9], Lillemäe et al. [13], and Peippo et al. [14]. Fatigue strength of weld-repaired cut edges has not been studied extensively so far. Jun et al. [15] carried out fracture and fatigue crack growth analyses on a weldrepaired railway rail. He found out that weld defects, such as porosity, lamella line cracks, and quick transitions in material hardness and microstructure, especially at the boundaries, could be the causes of the crack initiation. The crack growth was influenced by the magnitude of the residual stress at the surface. Akyel et al. [16] investigated the fatigue strength of repaired cracks in base material of high strength steels. The results show that most of the fatigue cracks initiated at the

Table 3 Cutting parameters

\begin{tabular}{lll}
\hline Oxy-fuel cutting & Velocity 1 (fast) & Velocity 2 (slow) \\
\hline Fuel gas (bar) & 0.8 & \\
Pressure of cutting oxygen (bar) & 6 & \\
Preheat temperature $\left({ }^{\circ} \mathrm{C}\right)$ & 20 & 390 \\
Cutting speed (mm/min) & 420 & Q2 \\
Estimated quality (ISO 9013) & Q4 & \\
\hline
\end{tabular}

start-stop points of the weld cap. The statistical analysis revealed that the characteristic fatigue strength of the repaired specimens is close to the detail category 160 of EN 1993-1-9 [17]. He concluded that the repair weld has a limited negative influence on the fatigue strength of the material. Another study of Akyel et al. [18] examined the fatigue strength of repaired welded connections made of very high strength steels. He showed that the fatigue strength of the fatigue damaged connection can be completely recovered by the established repair procedure.

In this investigation, fatigue tests were carried out on oxyfuel thermal cut edges with defect-free and faulty repairwelded samples to analyze the influence of competing notches on the fatigue strength. The stress ratio applied was $R=0.1$ under constant amplitude load. All samples were characterized in terms of hardness, roughness, and perpendicularity according to EN 1090 and ISO 9013.

\section{Experimental work}

The effect of repaired notches on thermal cut edges on the fatigue strength of two different steel grades with a minimum yield strength of 355 and $690 \mathrm{MPa}$ was analyzed. Mechanical properties of the steels were different. S355N are normalized rolled weldable fine grain structural steels with minimum yield strength of $355 \mathrm{MPa}$ and a carbon equivalent value (CEV) less than 0.42, EN 10025-3 [19], and S690Q are quenched and tempered high strength steel with a minimum yield strength of $690 \mathrm{MPa}$ and a carbon equivalent value less than 0.65, EN 10025-5 [20]. Samples were cut from a 20-mmthick plate.

Table 1 shows the detailed material properties. The chemical composition including the carbon equivalent value is presented in Table 2 . In addition, the cutting parameters are given in Table 3. 
Fig. 1 Dimensions of fatigue test samples in millimeters, top: S690Q cutting speed high quality 4, bottom: S355N cutting speed low quality $2+$ repaired notch
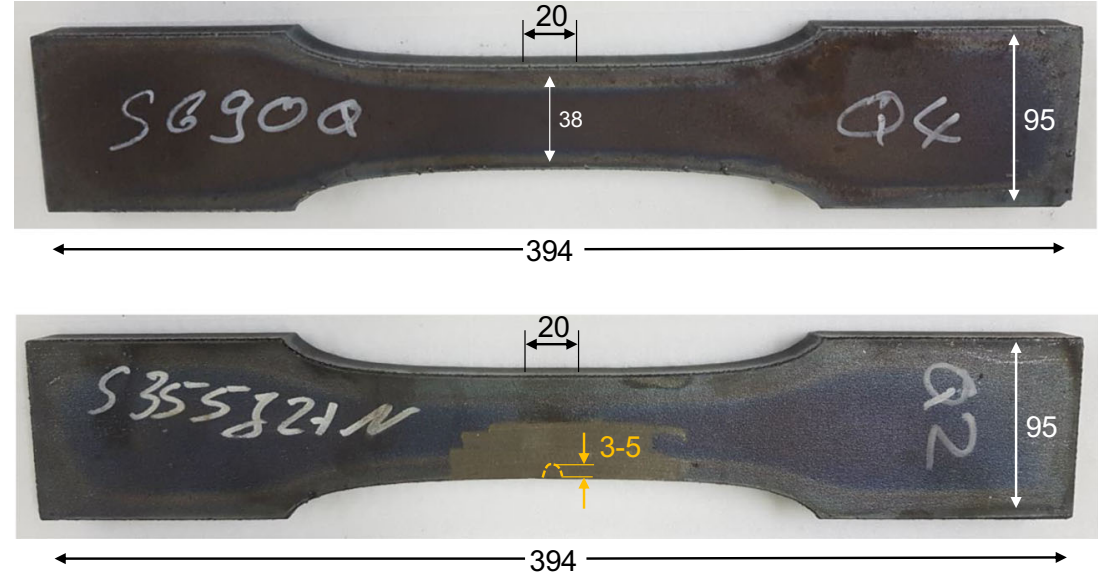

\subsection{Specimens}

The specimens used for fatigue tests were cut using thermal cutting processes. In this study, oxygen cutting was used. Steel plates had a thickness of $20 \mathrm{~mm}$. The geometry of the specimens was similar to previous work [6]. The samples were $394 \mathrm{~mm}$ long, and in the center, the specimens had a parallel length of $20 \mathrm{~mm}$ with a width of $38 \mathrm{~mm}$ in the critical cross section (Fig. 1). To analyze competing notches on the fatigue strength of cut plate edges, two series, one of each material, were purposely cut with defects in order to reproduce process dysfunctions of the industry. The resulting notches by the flame penetration were subsequently welded using metalactive gas welding GMAW135 with filler wire G3Si1 in welding position flat 1G [21], cf. MAG135 (PA) [22]. Therefore, samples were rotated $90^{\circ}$ around the $y$-axis (Fig. 2 ). The depth of the notch on the cut edge varies over the thickness of the specimen. At the top (entrance of the beam) the depth of the notch was about $5 \mathrm{~mm}$, and at the bottom (beam exit), it was about $3 \mathrm{~mm}$. Weld reinforcements were ground to a plane cut edge surface to recondition the specimen dimensions. Location of the notch is shown on the second specimen schematically at the bottom of Fig. 1.

\subsection{Cut edge conditions}

Geometrical and metallographic cut edge conditions were characterized. The location of roughness and hardness measurements are shown in Fig. 2. Hardness measurements were made at the cross section for the heat-affected zone (HAZ) as well as the base material (BM), see below. Further, cross-sectional A-A was defined to analyze the repaired notch in terms of hardness mapping and metallography analysis (Table 4). Notch was repaired using metal-active gas welding in $1 \mathrm{G}$ position (Fig. 3).

\subsubsection{Roughness measurements}

To determine the surface condition, roughness measurements were made on the surface of each specimens in accordance with ISO 4288 [23]. Using the MarSurf M 400 surface measuring instrument, measurements were carried out with the profile method over a length of $17.5 \mathrm{~mm}$. From each series, at least three specimens were measured. To include the roughness distribution over the specimen thickness, measurements were made at the top (entrance of the beam), in the middle, and at the bottom side (beam exit) of the cut edges. The maximum difference between the profile peak and the profile valley is averaged over five individual measuring sections; $R_{Z}$ is calculated of the five different $R_{Z(i)}$ as follows (Fig. 4) (Eq. 1) [17]:

$$
R_{Z}=\frac{1}{5} \sum_{i=1}^{5} R_{Z}(i)
$$

Fig. 2 Locations of roughness and hardness measurements

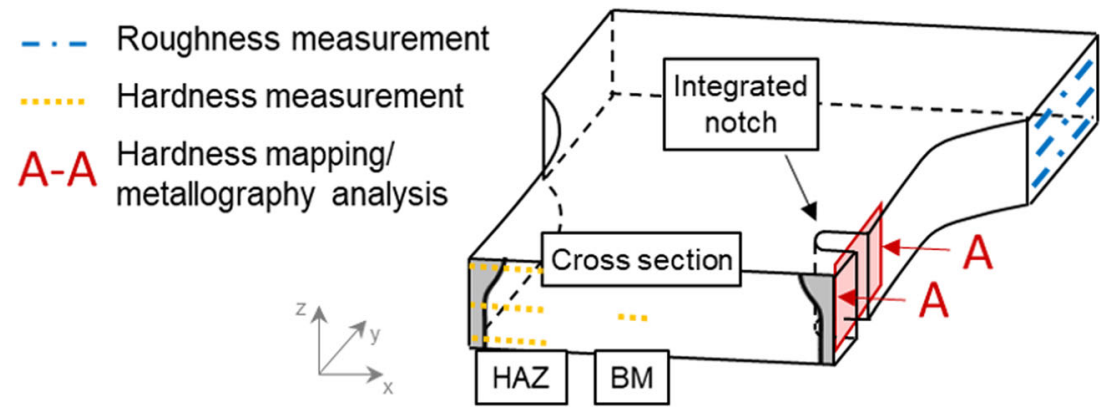


Table 4 Macroscopic surface analysis of the different series

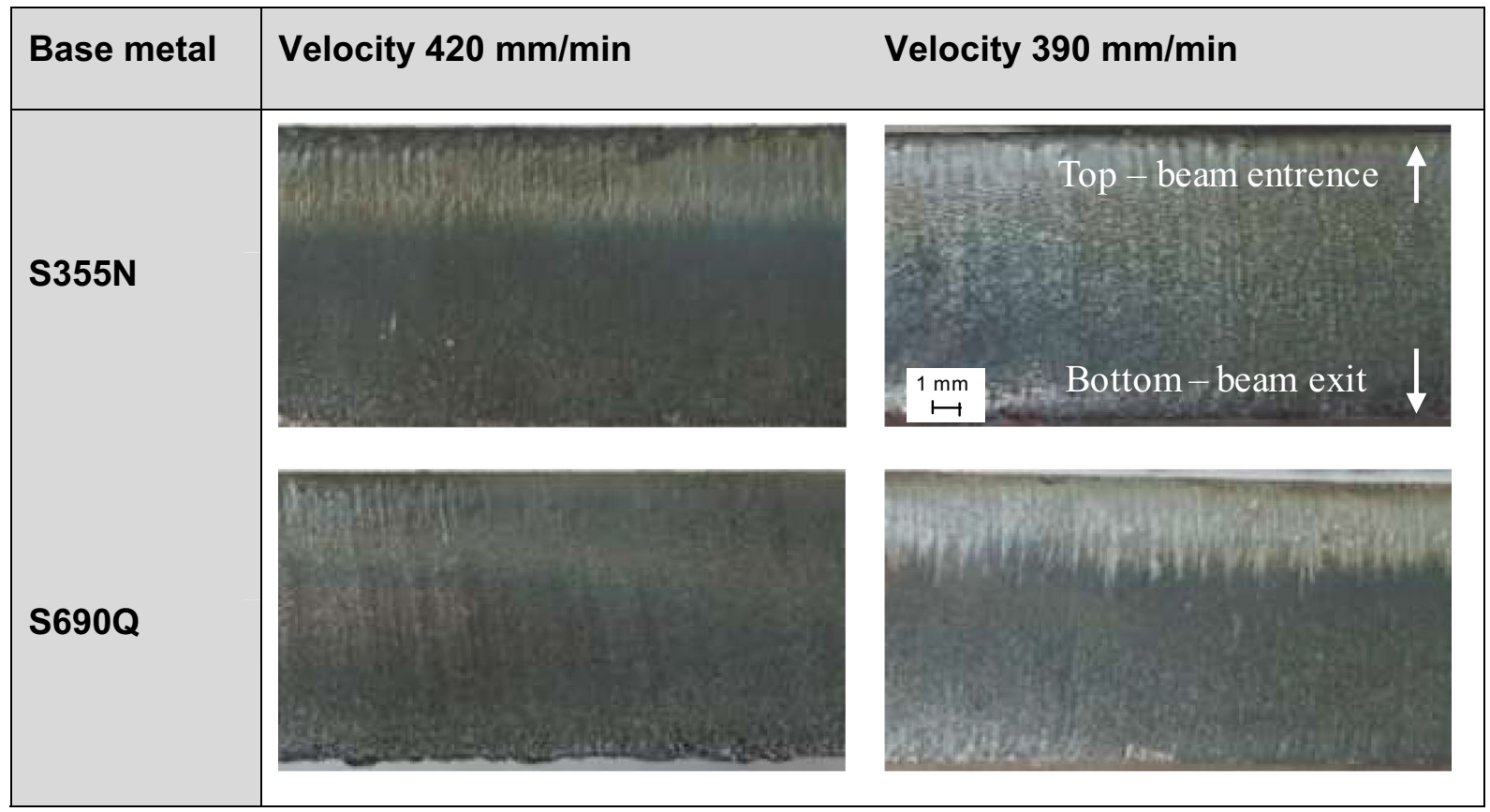

\subsubsection{Perpendicularity measurements}

Perpendicularity measurements were made on the specimens according to ISO 9013. Measurements were done on the cut edge surface. Tests were carried out with a triangulation laser to determine a height profile over the thickness. The perpendicularity is defined as the difference between lowest and highest value of the profile (Figure 5). On each specimen, five different locations were chosen to measure the perpendicularity.

\subsubsection{Hardness measurements and metallography analysis}

Hardness measurements were carried out from cross sections which have been cut from the dog-bone specimens by using a water-cooled abrasive cutter. The surface were ground using different abrasive paper, polished, and etched with a Nital solution $(2 \%)$ to visual the microstructure. The hardness in the HAZ of thermally cut edges was analyzed afterwards. Therefore, Vickers hardness (HV0.1) measurements were made for each series according to ISO 6507 [24]. Further, the hardness were measured on the cut edge surface of two series with the repaired notches (section A-A). Cut edges had to be prepared and ground to get a plane surface for the Vickers hardness (HV1) measurements.

\subsection{Fatigue tests}

Fatigue testing was conducted on servo-hydraulic test rigs at the Institute of Joining and Welding Technology at Technische Universität Braunschweig. The test load was applied force-controlled longitudinal to the cut edge with a constant amplitude load (CAL). The stress ratio applied was $R=$ $\sigma_{\min } / \sigma_{\max }=0.1$. Tests were stopped at specimen fracture. Table 5 shows the fatigue test program. The fatigue strength was determined in the finite life region between $1 \times 10^{5}$ and 1 $\times 10^{6}$. Run-outs (specimen without failure) were stopped at 5 million load cycles. The fatigue data was evaluated by linear regression without consideration of run-outs following the standard of DIN 50100 [25].

Fig. 3 Repaired specimen after grinding the weld reinforcements

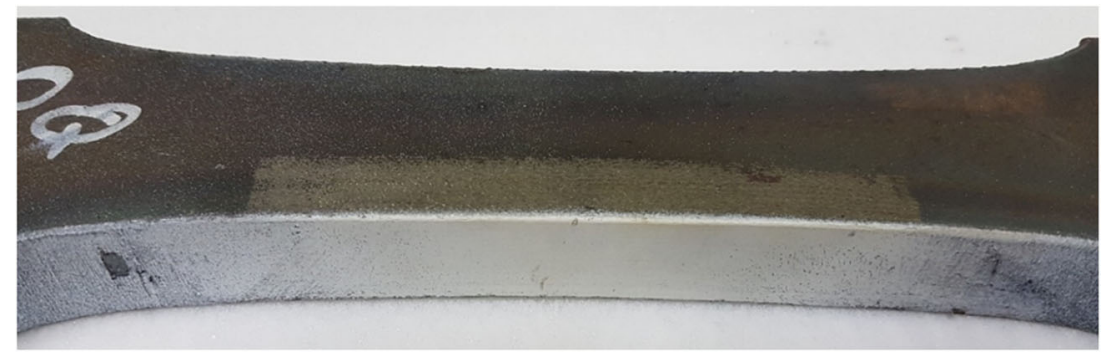


Fig. 4 Determination of the average surface roughness $R_{Z}$

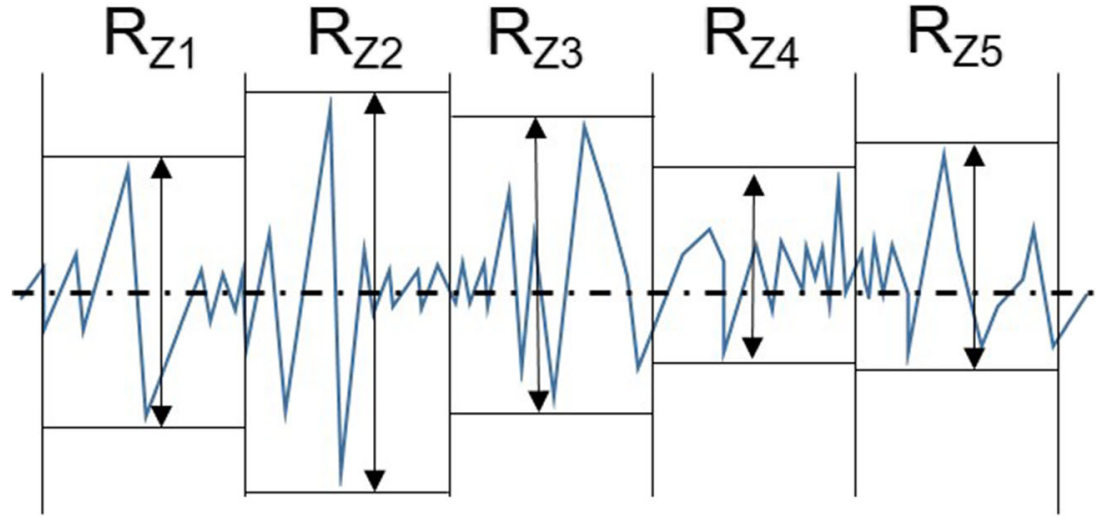

\section{Results}

\subsection{Roughness on the cut edge}

The measured roughness parameter on the cut edge is the average of the five highest peaks and lowest valleys $R_{Z}$ at the top, in the middle, and at the bottom of the cut edge surface. The results are summarized in Table 6. Macroscopical analyses from the cut edge surface show differences of the $R_{Z}$ over the thickness (Table 4). Thus, the arithmetical peak-topeak average roughness $R_{Z}$ was determined on the cut edge surface at three positions. The value ranges from 24.3 to $149 \mu \mathrm{m}$ over all results. On all series, a gradient over the thickness is seen. Lowest values are located at the top of the cut edge (24.3-84.2 $\mu \mathrm{m})$, mean values in the middle (72.4 $129.5 \mu \mathrm{m}$ ), and the highest values at the bottom of the surface (95-149 $\mu \mathrm{m})$.

To classify the values in the quality groups regarding ISO 9013, highest values have to be considered. Comparing the various series, it is observed that there is no big difference between the different base metals. However, the velocity of the cutting process has an influence on the roughness values.

The bar graph in Fig. 6 compares the different roughness values $R_{Z}$ at the bottom of the cut edge surface, because highest values were determined. Further, the limits of the

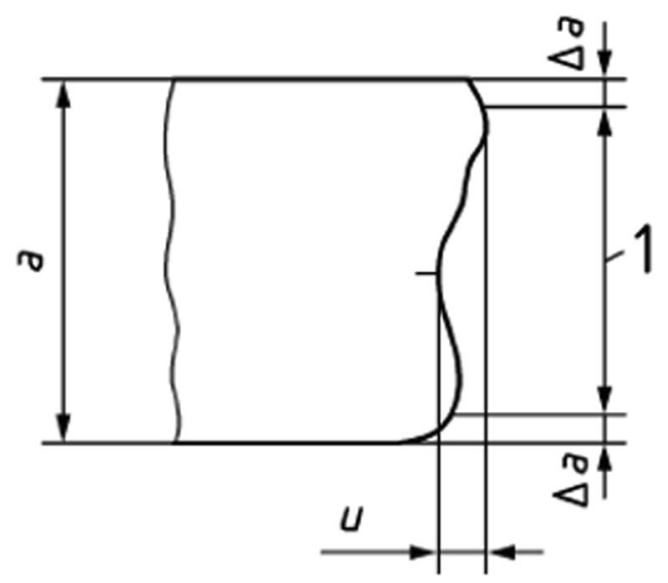

Fig. 5 Perpendicularity maximum $R_{Z}$ value for the specific plate thickness of $20 \mathrm{~mm}$ for the different quality groups are added. The roughness of the repaired section A-A was smoother than on the cut edge due to grinding of the weld reinforcements.

It is observed that all mean values of the series have to be classified in quality group 4 . The base metal has no influence of the roughness values. Contrary to the base metal, the velocity affects the roughness. Decreasing the cutting speed decreases the roughness at the cut edge as well, and therefore, the quality increases. Even though a higher quality range in the ISO 9013 is not reached.

\subsection{Perpendicularity measurements}

Besides the roughness measurements, perpendicularity measurements were made to characterize the cut edge quality regarding ISO 9013. The bar graph shows the various $u$ values defined as the difference between lowest and highest value of the profile including the error bars. Further, the limits of the maximum $u$ value for the specific plate thickness of $20 \mathrm{~mm}$ for the different quality groups are added.

The perpendicularity show also the same tendency. Series $1(\mathrm{~S} 355, u=0.65 \mu \mathrm{m})$ and $4(\mathrm{~S} 690, u=0.36 \mu \mathrm{m})$ with a velocity of $420 \mathrm{~mm} / \mathrm{min}$ have higher $u$ values compared with series $2(\mathrm{~S} 355, u=0.2 \mu \mathrm{m})$ and $5(\mathrm{~S} 690, u=0.18 \mu \mathrm{m})$ with a velocity of $390 \mathrm{~mm} / \mathrm{min}$. With the high cutting speed, S355N is classified in quality group 4 and S690Q in quality group 3. Decreasing the cutting speed decreases the perpendicularity at the cut edge as well, and therefore, the quality increases. Both materials are ranged in quality group 2 with the low velocity (Fig. 7).

\subsection{Metallography analysis and hardness measurements}

\subsubsection{Measurements at the cut edge}

The different cutting parameters affect the material close to the cut edge. The velocity of the cutting process and the following cooling rate have an influence on the size of the HAZ. Further, 
Table 5 Fatigue test data

\begin{tabular}{|c|c|c|c|c|c|c|}
\hline Test series & Steel grade & Cutting process & Velocity (mm/min) & Repaired notches & Thickness (mm) & Specimen tested \\
\hline 1 & $\mathrm{~S} 355 \mathrm{~N}$ & Oxy-fuel & 420 & No & 20 & 23 \\
\hline 2 & $\mathrm{~S} 355 \mathrm{~N}$ & Oxy-fuel & 390 & Yes & 20 & 12 \\
\hline 3 & $\mathrm{~S} 355 \mathrm{~N}$ & Oxy-fuel & 390 & No & 20 & 12 \\
\hline 4 & S690Q & Oxy-fuel & 420 & No & 20 & 21 \\
\hline 5 & S690Q & Oxy-fuel & 390 & Yes & 20 & 12 \\
\hline 6 & S690Q & Oxy-fuel & 390 & No & 20 & 9 \\
\hline
\end{tabular}

Table 6 Data of roughness measurements on the cut edge surface

\begin{tabular}{llllll}
\hline Test series & & & Top (beam entrance) & Middle & Bottom (beam exit) \\
\hline & & & $(\mu \mathrm{m})$ & $(\mu \mathrm{m})$ & $(\mu \mathrm{m})$ \\
1 & $\mathrm{~S} 355$ & $V_{1}=420 \mathrm{~mm} / \mathrm{min}$ & $53.2-68.2$ & $108.7-124.3$ & $121-149$ \\
2,3 & $\mathrm{~S} 355$ & $V_{2}=390 \mathrm{~mm} / \mathrm{min}$ & $24.3-44.5$ & $72.4-103.2$ & $107.4-122.2$ \\
4 & $\mathrm{~S} 690$ & $V_{1}=420 \mathrm{~mm} / \mathrm{min}$ & $50.9-84.2$ & $94.9-129.5$ & $117.6-145.2$ \\
5,6 & $\mathrm{~S} 690$ & $V_{2}=390 \mathrm{~mm} / \mathrm{min}$ & $28.6-43.2$ & $74.7-103.6$ & $95-114.6$ \\
\hline
\end{tabular}

the base metal and the related CEV of it determine the possible maximum hardness. To check the maximum hardness at the cut edge and to point out possible differences over the thickness, three hardness profiles were determined. Hardness measurements were done on the cross section at the top $(1 \mathrm{~mm}$ under the sample surface), in the middle, and at the bottom ( $1 \mathrm{~mm}$ over the sample bottom side).

Figure 8 shows hardness measurements for $\mathrm{S} 355 \mathrm{~N}$ and S690Q steel grades and the two different velocities used. Hardness profiles at the top marked as green cycles, in the middle as red squares, and at the bottom as blue triangles. Maximum permitted hardness values regarding EN 1090 are also added. All measurements were done at least $2 \mathrm{~mm}$ from both edges into the unaffected base material. Concerning the hardness measurements, the HAZ is $1-3 \mathrm{~mm}$ wide, depending on the base metal. In addition, the heat input at the top is higher which results in a wider HAZ. The maximum hardness value for S355N is $438 \mathrm{HV} 0.1$ and for S690Q $461 \mathrm{HV} 0.1$. It implicates a relatively increased hardening compared with the base material from 50 to $150 \%$. The hardness values exceed slightly the maximum permitted hardness value from the EN 1090.

\subsubsection{Measurements at the repaired notch}

To determine the heat-affected area and the hardness increase due to repair welding process, hardness mappings of the crosssectional A-A (Fig. 2) were carried out with Vickers hardness (HV1) for both materials. Figure 9 shows the hardness mapping of the repaired notch from S355N (top) and S690Q (middle). Further, a hardness profile over the weld seam $1 \mathrm{~mm}$ under the surface is carried out of both materials. The different values of the base material of S355N-approx. $200 \mathrm{HV} 1$ - and
Fig. $6 R_{Z}$ values at the bottom of the cut edge surface

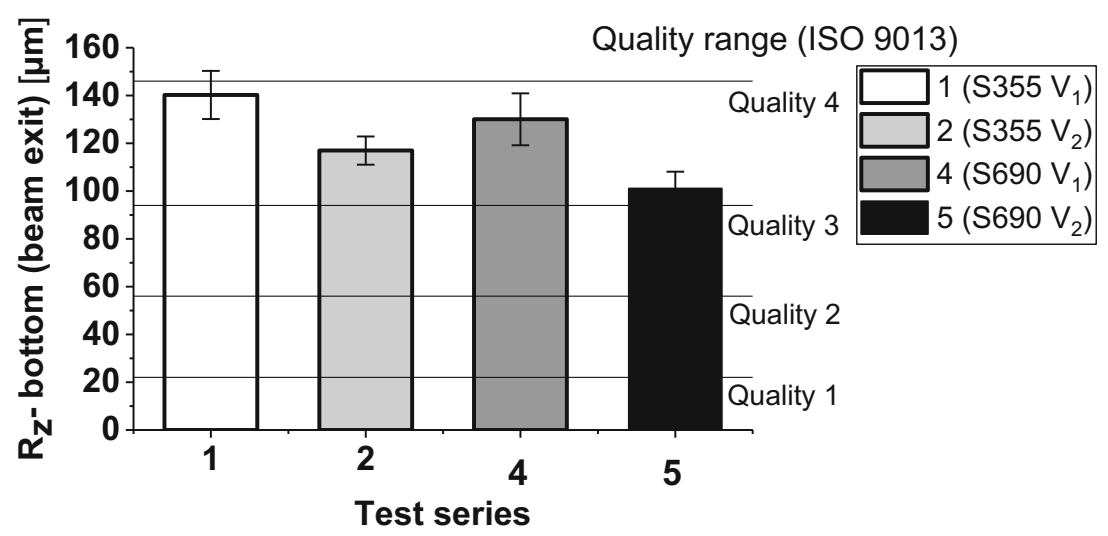


Fig. 7 Perpendicularity of the cut edges of the different series
Quality range (ISO 9013)

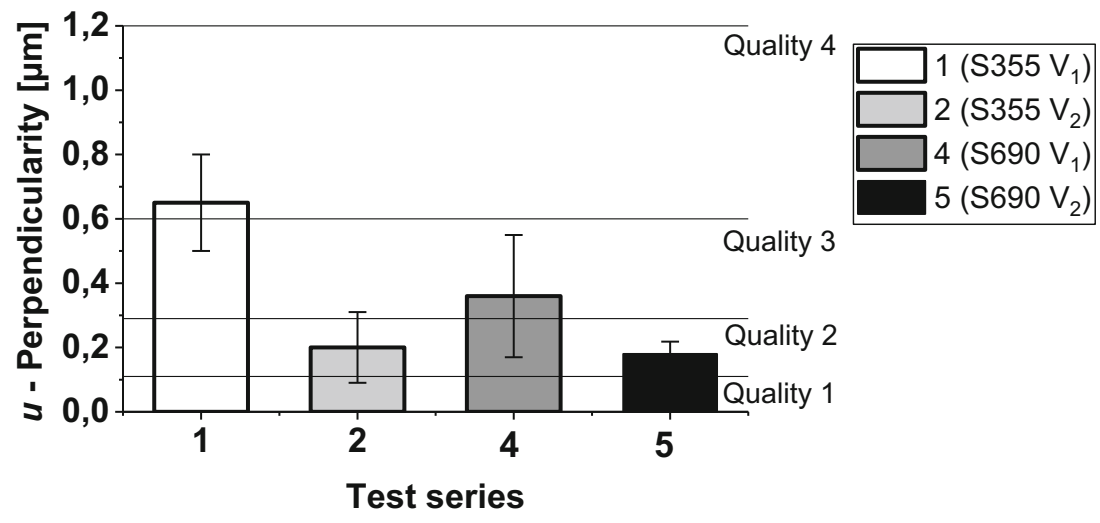

S690Q - approx. 300 HV1 - are visible. Also, the weld seam and the HAZ are well seen. At the top of both specimens, the weld seam is significantly wider than in the middle and at the bottom. The inserted notch by the oxy-fuel flame seems to be larger at the top. The maximum hardness values on the cross section are $436 \mathrm{HV} 1$ for S355N and $449 \mathrm{HV} 1$ for S690Q.

The hardness values do not exceed the maximum permitted hardness value from the EN 1090. Further, the values do not exceed the maximum hardness values from the cut edge measured (Figure 8).
The hardness profiles show similar curves of both measurements except the location and width of the HAZ and the values of the base material. The maximum hardness value is also similar about $410 \mathrm{HV} 1$.

Due to repair welding with filler wire, pores and imperfections can occur in the weld seam. Metallography analysis on the weld seam has shown pores on $25 \%(6 / 24)$ of the samples. Imperfection has a radius up to $0.3 \mathrm{~mm}$. Three out of the whole samples had failure at the repair weld induced by imperfections (Table 7).
Fig. 8 Hardness measurements on the cross section at the top, middle, and bottom of the cut edge. Variation of steel grade and velocity
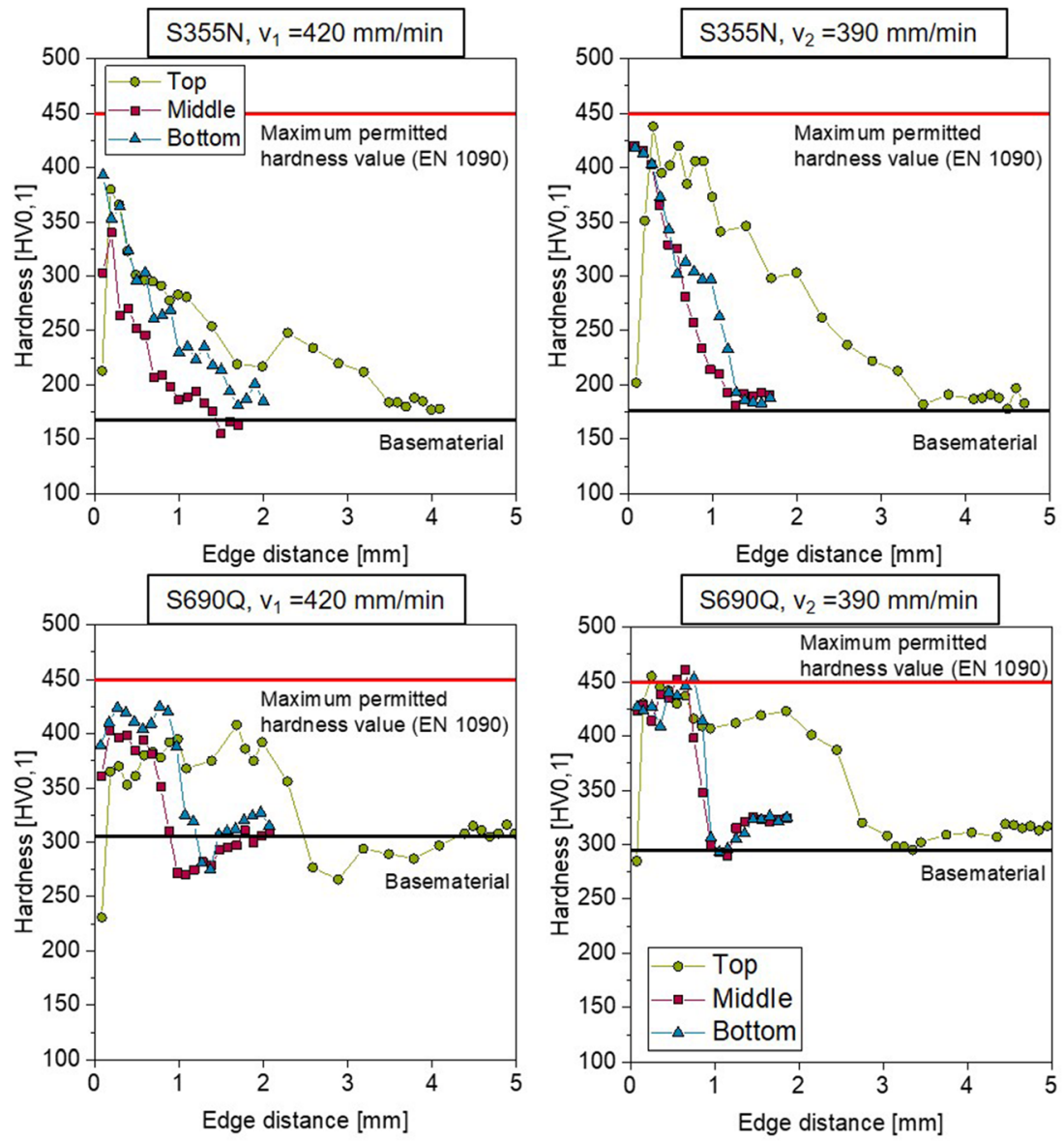

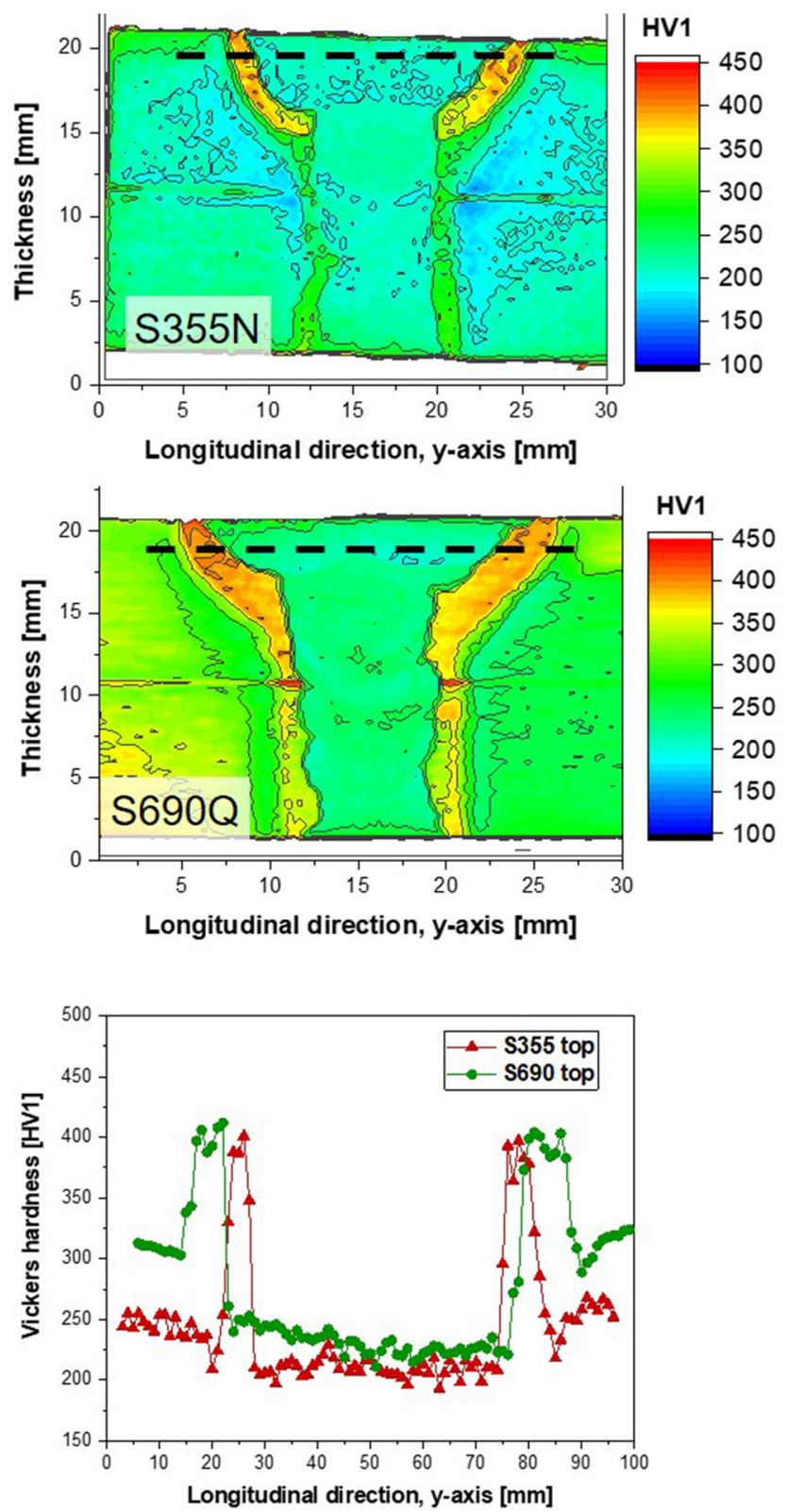

Fig. 9 Hardness mapping of the repaired notch from S355N (top) and S690Q (middle). Vickers hardness profile $1 \mathrm{~mm}$ under the surface (bottom)

\subsection{Fatigue test results}

All fatigue test results are summarized in Table 6. It shows the number of specimens including run outs, the slope of the S-N curve, $\log \mathrm{C}$ (intercept of the $\mathrm{S}-\mathrm{N}$ curve with the $y$-axis), the nominal fatigue strength $\Delta \sigma$ at 2 million load cycles (POS = $50 \%$ ), the nominal fatigue strength $\Delta \sigma$ at 2 million load cycles (POS $=97.7 \%$ ), corrected to stress ratio $R=0.5$, and the crack initiation location (cut edge surface/corner/plate surface). The corresponding survival probability of $97.7 \%$ is calculated by using Eq. 2: $\log N=(\log C-k s t d v(\log C))-m \log \Delta \sigma$

with $k=1.645\left(1+\frac{1}{\sqrt{n}}\right)$

and the fatigue enhancement factor for the effective stress ratio is used from Hobbacher [26]:

$f(R)=1.16$

The fatigue test results of all series are shown in the following two figures (Figs. 10 and 11). Each figure presents one material with the different cutting speeds used and the series with the repaired notch. Two design curves from the IIW recommendations (FAT 125, FAT140) are also added-well known that the fatigue data evaluated cannot directly be compared with IIW FAT values.

Fig. 10 shows the test data from oxy-fuel cut specimens made from $\mathrm{S} 355 \mathrm{~N}$ plates. Fatigue strength is sum up at the bottom left of the diagrams. Test data of $\mathrm{S} 355 \mathrm{~N} \mathrm{v}_{1}$ as well as S690Q $v_{1}$ was merged with data of previous studies with the same cutting parameters [6].

Fatigue strength at 2 million load cycles of $\mathrm{S} 355 \mathrm{~N} \mathrm{v}_{1}$ was determined to $\Delta \sigma=199 \mathrm{MPa}$ with a survival possibility (POS) of $50 \%$. The regression line was calculated to $k=4.4$ without considering run outs. The benefit of a low cutting speed is primary at higher numbers of load cycles. The fatigue strength increase was determined to $\Delta \sigma=249 \mathrm{MPa}$ at 2 million load cycles with a slope of $k=6.0$. It is an increase of $25 \%$ of fatigue strength compared with the fast velocity $v_{1}=420$ $\mathrm{mm} / \mathrm{min}$. No significant decrease of the repaired notch series was observed. Fatigue strength results show similar values of $\Delta \sigma=248 \mathrm{MPa}$ and a slope of $k=6.8$.

The test data of the material S690Q are shown in Fig. 11. Fatigue strength at 2 million load cycles of S690Q $v_{1}$ was determined to $\Delta \sigma=183 \mathrm{MPa}(\mathrm{POS}=50 \%)$. The slope was calculated to $k=3.0$. The fatigue strength of the series with the low velocity increased to $\Delta \sigma=240 \mathrm{MPa}$ at 2 million load cycles with a slope of $k=4.3$. It is an increase of $31 \%$ of fatigue strength compared with the fast velocity $v_{1}=420 \mathrm{~mm} / \mathrm{min}$. No significant decrease of the repaired notch series was observed. Fatigue strength results show similar values of $\Delta \sigma=238 \mathrm{MPa}$ and a slope of $k=3.8$.

\section{Discussion}

The geometrical details at the cut edges were determined according to the ISO 9013. Roughness and perpendicularity measurements were conducted on all different series. Quality differences were observed by using various velocities of the cutting process. $R_{Z}$ values are classified in quality group 4 . Decreasing the cutting speed decreases the roughness at the 
Table 7 Fatigue test data

\begin{tabular}{|c|c|c|c|c|c|c|c|c|}
\hline Test series & $\begin{array}{l}\text { Stress ratio } \\
R\end{array}$ & $\begin{array}{l}\text { Number of samples (run } \\
\text { outs) }\end{array}$ & $\begin{array}{l}\text { Slope } \\
k\end{array}$ & $\begin{array}{l}\log \\
\mathrm{C}\end{array}$ & SD & $\begin{array}{l}\Delta \sigma(2 \mathrm{E} 6) \\
50 \%\end{array}$ & $\begin{array}{l}\Delta \sigma(2 \mathrm{E} 6) 97.7 \% \text { corrected to } R= \\
0.5\end{array}$ & $\begin{array}{l}\text { Crack } \\
\text { initiation } \\
\text { S-C-P }\end{array}$ \\
\hline $\mathrm{S} 355 \mathrm{~N} v_{1}$ & 0.1 & $23(2)$ & 4.4 & 16.3 & 0.12 & 200 & 151 & $2-18-1$ \\
\hline $\begin{array}{c}\mathrm{S} 355 \mathrm{~N} v_{2} \\
(\mathrm{Ke})\end{array}$ & 0.1 & $12(1)$ & 6.8 & 22.5 & 0.14 & 248 & 194 & $1(1)-7-4(2)$ \\
\hline $\mathrm{S} 355 \mathrm{~N} v_{2}$ & 0.1 & $12(1)$ & 6.0 & 20.7 & 0.15 & 249 & 189 & $2-4-6$ \\
\hline S690Q $v_{1}$ & 0.1 & $21(2)$ & 3.0 & 13.2 & 0.1 & 184 & 136 & $4-17-0$ \\
\hline $\begin{array}{c}\mathrm{S} 690 \mathrm{Q} v_{2} \\
(\mathrm{Ke})\end{array}$ & 0.1 & $12(2)$ & 3.8 & 15.4 & 0.13 & 239 & 174 & $0-7-3$ \\
\hline S690Q $v_{2}$ & 0.1 & $9(1)$ & 4.3 & 16.5 & 0.04 & 240 & 197 & $3-4-1$ \\
\hline
\end{tabular}

$S$ cut edge surface, $C$ corner, $P$ plate surface, $(x)$ crack initiation in the repaired notch

cut edge, which comes up with a higher quality. Even though a higher quality range in the ISO 9013 is not reached. The perpendicularity show also the same tendency. Decreasing the velocity decreases the perpendicularity at the cut edge as well, and therefore, the quality increases. Both base metals (S355N and S690Q) are ranged in quality group 2 with the low velocity.

The hardness measurements at cut edge and at the repaired notch show that the maximum hardness values mainly comply with the EN 1090. Only three points at S690 $v_{2}$ exceed the value of $2.5 \%$. Higher hardness values can be explained by using a small penetration force HV0.1 and HV1 compared with the standard HV10. Several studies show that the use of HV10 in this area is not reasonable [27]. Hardness at the competing repaired notch show similar or lower values. Therefore, premature failure in case of the metallurgical notch in the repaired area is not expected.
The fatigue data evaluated here (Figs. 10 and 11) cannot directly be compared with IIW FAT values. The fatigue data has to be corrected for the stress ratio of $R=0.5$ (IIW). Further, the data is analyzed based on $50 \%$ probability of survival. Test results should be analyzed to produce characteristic values. These are values that represent $95 \%$ survival probability (i.e., $5 \%$ failure probability) calculated from the mean on the basis of a two-sided confidence of $75 \%$ corresponding to a survival probability of $97.7 \%$ and adjust for a stress ratio of $R$ $=0.5[26]$.

Fig. 12 shows the fatigue strength results $\Delta \sigma$ (2E6) $97.7 \%$, $m=$ var., $R_{\text {cor }}=0.5$. All series exceed FAT 125 . The cutting speed affects the roughness and the perpendicularity on the cut edge. Due to reduced cutting speeds, the roughness and the perpendicularity decrease also. This results in an increase of the fatigue strength in all tested series in this study. The defect on the cut edges is reduced as critical details were the cracks
Fig. 10 Fatigue test data of oxyfuel cut plate edges, S355N, $20 \mathrm{~mm}$ thick with varies velocities and repaired notch $(\mathrm{Ke})$

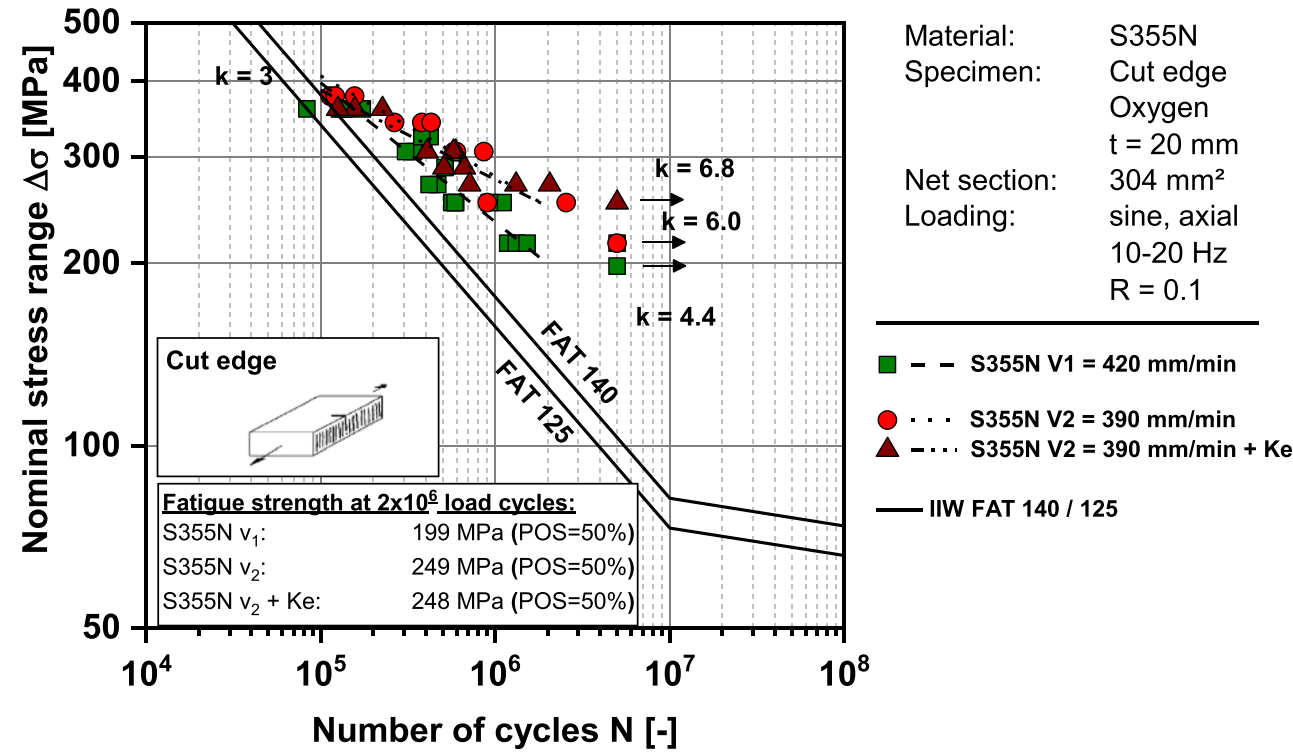


Fig. 11 Fatigue test data of oxyfuel cut plate edges, S690Q, $20 \mathrm{~mm}$ thick with varies velocities and repaired notch $(\mathrm{Ke})$

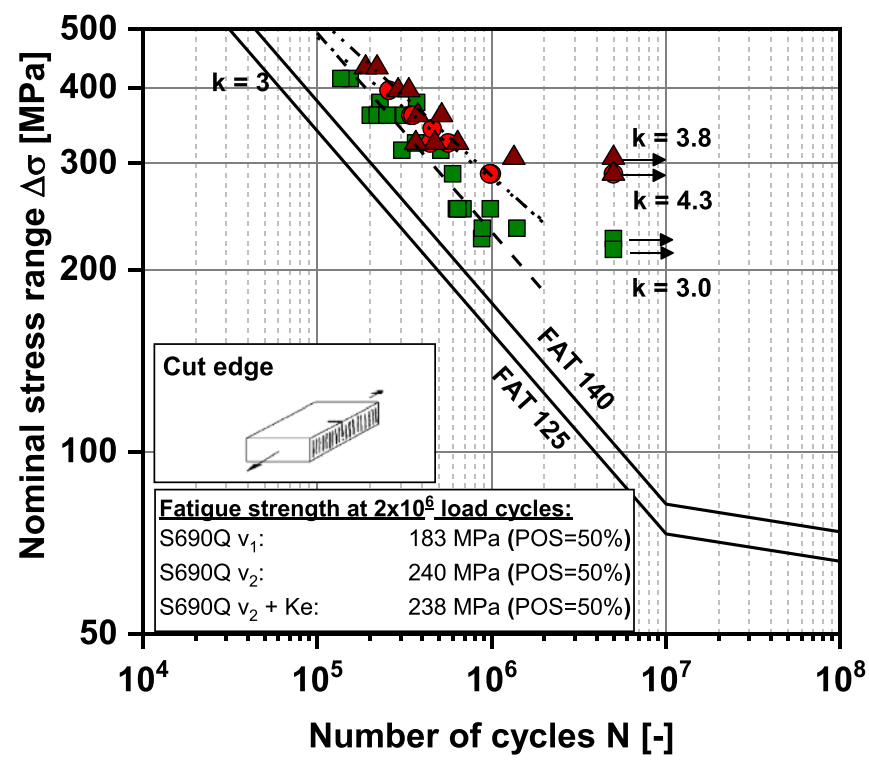

Material:

S690Q

Specimen: Cut edge

Oxygen

$\mathrm{t}=20 \mathrm{~mm}$

Net section: $\quad 304 \mathrm{~mm}^{2}$

Loading: sine, axial

$10-20 \mathrm{~Hz}$

$\mathrm{R}=0.1$

- $-\mathrm{S} 690 \mathrm{Q} \mathrm{V} 1=420 \mathrm{~mm} / \mathrm{min}$

. . S690Q V2 $=390 \mathrm{~mm} / \mathrm{min}$

- ... S690Q V2 $=390 \mathrm{~mm} / \mathrm{min}+\mathrm{Ke}$

— IIW FAT $140 / 125$ might start. Series with the low velocity achieve FAT 160 in all cases equal to base material samples.

The series with the repaired notch in the critical cross section by using metal-active gas welding in this study fulfil the standards of the IIW recommendations and do not show any significant reduction of the fatigue strength due to the determined pores or other metallurgical notches on the cut edge. However, fracture surface analysis show that for S355N specimens, three of the observed defects in the weld seam were determined as the critical defect for the crack initiation.

\section{Summary}

The document investigated experimentally the influence of competing notches on the fatigue strength of cut plate edges.
Fatigue tests were conducted on oxy-fuel cut plate edges with constant amplitude loading at a stress ratio of $R=0.1$. Two different materials S355N and S690Q with a plate thickness of $20 \mathrm{~mm}$ were considered. Further, different cut edge qualities were adjusted by changing the velocity of the cutting process. Two series were purposely cut with defects in order to reproduce process dysfunctions in the industry and subsequently repaired using metal-active gas welding.

Series with the repaired notch fulfil the standards of the IIW recommendations and do not show any reduction of the fatigue strength due to the determined pores in the weld seam.

In the case of fatigue strength, dysfunctions of the industry can subsequently repaired using metal-active gas welding. The weld reinforcements have to be ground to a plane cut edge surface. It is recommended to do a visual inspection of the repaired surface to determine possible huge pores.
Fig. 12 Fatigue strength $\Delta \sigma$ (2E6) $97.7 \%, m=$ var., $R_{\text {cor }}=0.5$

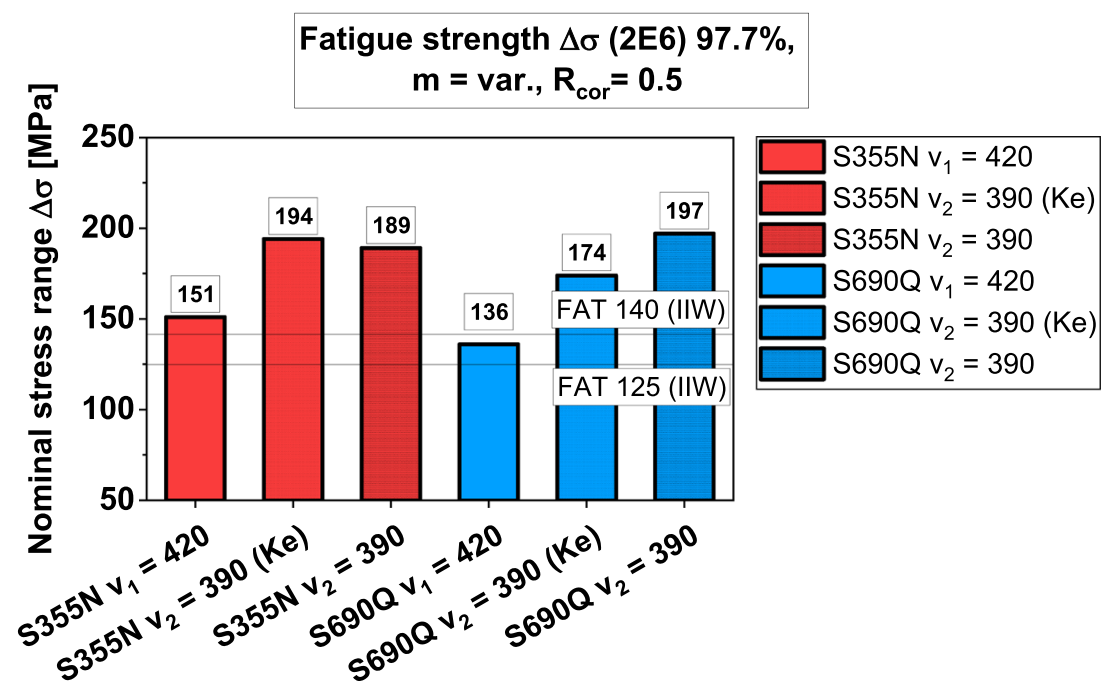




\section{Appendix}

Table 8 Raw data

$\overline{\mathrm{S} 355 \mathrm{~N} v_{1}}$

Test specimen Load ratio Nominal stress range $\quad$ Fatigue life

(index)

oad ratio

(MPa) (cycles)

$\begin{array}{lll}01 & 01\end{array}$

$(-)$

270

01_02

0.1

252

01_03

0.1

270

01_04

0.1

252

01_05

0.1

360

0106

0.1

360

0107

0.1

306

0108

0.1

216

01_09

0.1

306

01_10

0.1

252

01_11

0.1

360

01_12

0.1

360

01_13

0.1

0.1

360

01_14

0.1

324

01_15

0.1

324

01_16

01_17

0.1

288

288

01_18

0.1

$$
252
$$

01_19

0.1

252

01_20

0.1

216

01_21

01_22

01_23

0.1

0.1

0.1

216

198

216

$\mathrm{S} 355 \mathrm{~N} v_{2}$

(index)

03_01

03 -02

03_03

03_04

03_05

03 -06

03_07

03 -08

03 -09

03_10

03_11

03_12

$\mathrm{S} 355 \mathrm{~N} v_{2}+\mathrm{Ke}$

(index)

02_01

02_02

02_03

(

(-)

(MPa)

378

378

378

342

342

342

306

306

306

252

252

216

0.1

(MPa)

360

360

360

565,846

128,197

83,690

340,447

$1,179,480$

306,554

594,193

134,747

138,852

173,888

425,448

381,537

517,881

517,229

927,000

590,000

$1,324,000$

$1,524,000$

$5,000,000$

$5,000,000$

(cycles)

113,359

156,630

264,989

381,471

431,486

582,597

861,479

599,853

$2,556,690$

900,809

$5,000,000$

(cycles)

226,548

125,624

0.1

$(-)$
0.1
Table 8 (continued)

$\mathrm{S} 355 \mathrm{~N} v_{1}$

\begin{tabular}{llll}
\hline Test specimen & Load ratio & Nominal stress range & Fatigue life \\
\hline 02_04 & 0.1 & 306 & 406,813 \\
02_05 & 0.1 & 288 & 668,305 \\
$02 \_06$ & 0.1 & 288 & 510,794 \\
$02 \_07$ & 0.1 & 270 & $1,317,400$ \\
02_08 & 0.1 & 270 & $2,049,030$ \\
02_10 & 0.1 & 306 & 593,303 \\
$02 \_11$ & 0.1 & 306 & 576,453 \\
$02 \_12$ & 0.1 & 252 & 226,548 \\
S690Q $v_{1}$ & & &
\end{tabular}

(index)

04_01

04_02

04_03

04_04

04_05

04_06

04_07

04_08

04_09

04_10

04_11

04_12

04_13

04_14

04_15

04_16

04_17

04_18

04_19

121,808

04_20

04_21

S690Q $v_{2}$

(index)

06_01

06_02

06_03

06_04

06_05

06_06

06_07

06_08

06_09

S690Q $v_{2}+\mathrm{Ke}$

(index)

05_01

05_02

05_03

$\begin{array}{ll}(-) & (\mathrm{M} \\ 0.1 & 378 \\ 0.1 & 378\end{array}$

$0.1 \quad 252$

$\begin{array}{ll}0.1 & 252\end{array}$

$0.1 \quad 360$

$0.1 \quad 360$

$0.1 \quad 414$

$0.1 \quad 414$

$0.1 \quad 315$

$0.1 \quad 315$

$0.1 \quad 225$

$0.1 \quad 360$

$0.1 \quad 360$

$\begin{array}{ll}0.1 & 360\end{array}$

$\begin{array}{ll}0.1 & 324 \\ 0.1 & 288\end{array}$

$0.1 \quad 252$

$0.1 \quad 252$

$0.1 \quad 234$

$0.1 \quad 234$

$0.1 \quad 225$

$0.1 \quad 216$

(cycles)

372,305

228,954

687,503

629,353

313,824

201,345

154,784

136,571

511,290

305,731

876,625

221,073

251,292

366,979

598,118

641,768

985,738

887,104

$1,400,390$

$5,000,000$

$5,000,000$

(cycles)

995,698

975,552

445,482

565,063

457,415

344,273

353,763

258,100

5E6

(cycles)

291,116

516,897

472,609

0.1

\begin{abstract}
360
\end{abstract}

\begin{abstract}
-
\end{abstract}


Table 8 (continued)

\begin{tabular}{llll} 
S355N $v_{1}$ & & & \\
\hline Test specimen & Load ratio & Nominal stress range & Fatigue life \\
\hline 05_04 & 0.1 & 396 & 335,200 \\
05_05 & 0.1 & 324 & 367,710 \\
05_06 & 0.1 & 432 & 189,000 \\
05_07 & 0.1 & 432 & 220,182 \\
05_08 & 0.1 & 306 & $1,342,580$ \\
05_09 & 0.1 & 360 & 377,553 \\
05_10 & 0.1 & 324 & 636,450 \\
$05 \_11$ & 0.1 & 306 & $5,000,000$ \\
$05 \_12$ & 0.1 & 288 & $5,000,000$
\end{tabular}

Nomenclature CAL, Constant amplitude load; BM, Base material; $\mathrm{CEV}$, Carbon equivalent value; HAZ, Heat-affected zone; HFMI, High frequency mechanical impact; HV, Vickers hardness; $k$, Slope $k$ of the S$\mathrm{N}$ diagram; $\log \mathrm{C}$, Intercept of the S-N curve with the $y$-axis; POS, Probability of survival; $R$, Stress ratio; $R_{\mathrm{eH}}$, Yield strength; $R_{m}$, Tensile strength; $R_{Z}$, Average roughness $(\mu \mathrm{m}) ; \Delta \sigma$, Nominal stress range (MPa); $\mathrm{SD}$, Standard deviation for $\log C ; t$, Thickness specimens (mm); $u$, Perpendicularity $(\mathrm{mm})$; UCI, Ultrasonic contact impedance

Funding Open Access funding enabled and organized by Projekt DEAL. The presented investigations were supported by the Arbeitsgemeinschaft industrieller Forschungsvereinigungen (AiF) in the project $18.789 \mathrm{~N}$ "Bedeutung der Qualitätsmerkmale freier Schnittkanten nach DIN EN 1090 für deren Schwingfestigkeit unter Berücksichtigung von Eigenspannungen."

Open Access This article is licensed under a Creative Commons Attribution 4.0 International License, which permits use, sharing, adaptation, distribution and reproduction in any medium or format, as long as you give appropriate credit to the original author(s) and the source, provide a link to the Creative Commons licence, and indicate if changes were made. The images or other third party material in this article are included in the article's Creative Commons licence, unless indicated otherwise in a credit line to the material. If material is not included in the article's Creative Commons licence and your intended use is not permitted by statutory regulation or exceeds the permitted use, you will need to obtain permission directly from the copyright holder. To view a copy of this licence, visit http://creativecommons.org/licenses/by/4.0/.

\section{References}

1. Radaj D, Vormwald M (2007) Ermüdungsfestigkeit: Grundlagen für Ingenieure, 3, neubearbeitete und erweiterte Auflage. Berlin: Springer-Verlag

2. Läpple V (2006) Introduction to strength theory: textbook and exercise book, 4., aktualisierte Auflage. Springer-Fachmedien, Wiesbaden (in German)
3. Nussbaumer A, Günther H-P (2006) Grundlagen und Erläuterung der neuen Ermüdungsnachweise nach Eurocode 3, StahlbauKalender

4. Sperle J-O (2007) Influence of Parent Metal Strength on the Fatigue Strength of Parent Material with Machined and Thermally Cut Edges. Weld World 52:79-92

5. Cicero S, García T, Álvarez JA et al (2016) Fatigue behaviour of structural steels with oxy-fuel, plasma and laser cut straight edges. Definition of Eu-rocode 3 FAT classes. Eng Struct 111:152-161

6. Diekhoff P, Hensel J, Nitschke-Pagel T, Dilger K (2019) Fatigue strength of thermal cut edges - influence of ISO 9013 quality groups. Weld World 63(2):349-363

7. Diekhoff P, Hensel J, Nitschke-Pagel T, Dilger K (2020) Investigation on fatigue strength of cut edges produced by various cutting methods for high strength steels. Weld World 64:545-561

8. Marquis GB, Barsoum Z (2016) IIW Recommendations for the HFMI treatment: for improving the fatigue strength of welded joints. Springer Science+Business Media Singapore, Singapur

9. Stenberg T, Lindgren E, Barsoum Z et al (2017) Barmicho I (2017) Fatigue assessment of cut edges in high strength steel - Influence of surface quality. Mater Sci Eng Tech 48(6) 556-569

10. DIN EN 1090 (2017) Execution of steel structures and aluminum structures - part 2: technical requirements for steel structures; German and English version EN 1090-2.

11. DIN EN ISO 9013 (2002) Thermal cutting — classification of thermal cuts - geometrical product specification and quality tolerances (ISO/DIS 9013:2014), Geneva, Switzerland.

12. Remes H, Korhonen E, Lehto P, Romanoff J, Niemelä A, Hiltunen P, Kontkanen T (2013) Influence of surface integrity on the fatigue strength of high-strength steels. J Constr Steel Res 89(9):21-29

13. Lillemäe I, Liinalampi S, Lehtimäki E, Remes H, Lehto P, Romanoff J, Ehlers S, Niemelä A (2017) Fatigue strength of high strength steel after shipyard production process of plasma cutting, grinding and sandblasting, IIW Document XIII-2695-17. International Institue of Welding, Shanghai

14. Peippo J, Björk T, Nykänen T A novel method for fatigue assessment of steel plates with thermally cut edges.

15. Jun H-K, Seo J-W, Jeon I-S, Lee S-W, Chang Y-S (2016) Fracture and fatigue crack growth analyses on a weld-repaired railway rail. Eng Fail Anal 59:478-492

16. Akyel A, Kolstein MH, Bijlaard SSK (2017) Fatigue strength of repaired cracks in base material of high strength steels. J Constr Steel Res 139:374-384

17. European Standard (2005) Eurocode 3: design of steel structurespart 1-9: fatigue, EN 1003-1-9, Brussels, Belgium.

18. Akyel A, Kolstein MH, Bijlaard SSK (2018) Fatigue strength of repaired welded connections made of very high strength steels. Eng Struct 161:28-40

19. DIN EN 10025-3 (2011) Hot rolled products of structural steelspart 4: technical delivery conditions for thermomechanical rolled weldable fine grain structural steels; German version EN 10025-3.

20. DIN EN 10025-5 (2011) Hot rolled products of structural steelspart 5: technical delivery conditions for structural steels with improved atmospheric corrosion resistance; German version EN 10025-5.

21. AWS A3.0M/A3.0 (2010) Standard welding terms and definitions including terms for adhesive bonding, brazing, soldering, thermal cutting, and thermal spraying .

22. DIN EN ISO 6947 (2011) Welding and allied processes - welding positions (ISO 6947:2011). 
23. DIN EN ISO 4288 (1998) Surface texture: profile method-rules and procedures for the assessment of surface texture. Beuth Verlag, Berlin

24. DIN EN ISO 6507-1 Metallic materials - Vickers hardness testpart 1: test method (ISO/DIS 6507-1:2016).

25. DIN 50100 (2015) Load controlled fatigue testing - execution and evaluation of cyclic tests at constant load amplitudes on metallic specimens and components.
26. Hobbacher A (2009) IIW recommendations for fatigue design of welded joints and components WRC, Welding Research Council Bulletin, WRC 520.

27. Berg J, Stranghöner N, Gorbachov A (2012) Influence of thermal cutting methods on the hardness of free edge regions of structural steel. Forschungsbericht, Duisburg

Publisher's note Springer Nature remains neutral with regard to jurisdictional claims in published maps and institutional affiliations. 